\title{
O PROCESSO DE CONSTITUIÇÃO DO SEU QUADRO DE PROFESSORES NA ESCOLA INDUSTRIAL DE NATAL (1942-1968)
}

\section{THE PROCESS OF CONSTITUTION OF THE TEACHER FRAMEWORK AT THE}

\author{
INDUSTRIAL SCHOOL OF NATAL (1942-1968)
}

\author{
Nina Maria da Guia de Sousa Silva ${ }^{1}$ \\ Instituto Federal de Educação, Ciência e Tecnologia - IFRN \\ Olivia Morais de Medeiros Neta2 \\ Universidade Federal do Rio Grande do Norte - UFRN
}

\section{Resumo}

Este trabalho tem como objetivo analisar, no período de 1942 a 1968, como a Escola Industrial de Natal (EIN) organizou o seu quadro de professores em vista ao atendimento às demandas provenientes de um currículo voltado para a formação de alunos cumpridores das normas estabelecidas e, sobretudo, aptos ao exercício de uma atividade profissional. O referencial teóricometodológico utilizado neste trabalho se centra na análise qualitativa, dando ênfase aos documentos históricos existentes no arquivo da escola, hoje denominada Instituto Federal de Educação, Ciência e Tecnologia do Rio Grande do Norte-IFRN. Constituem o conjunto desses documentos portarias e ofícios da Direção da Escola, livros de posse da Escola Industrial de Natal (1940 a 1959; 1960 a 1968), pastas individuais dos professores e fotografias que expressam flagrantes do processo de formação desses professores e de algumas de suas práticas educativas. Neste estudo, realçamos a análise, principalmente, da Lei Orgânica do Ensino Industrial (decreto-lei no 4.073/1942), da Lei 3.552 e do Decreto oㅜ 47.038, de 1959, objetivando identificar como essa instituição de ensino se apropriou e utilizou essas distintas legislações, tendo em vista o processo de constituição do corpo docente dessa escola. Também privilegiamos depoimentos orais de ex-professores que fizeram parte do corpo docente da Escola Industrial de Natal no período em estudo. Os autores Julia (2001) e Fonseca (1961) ajudam-nos a compreender como um conjunto de normas e ações desenvolvidas no âmbito da EIN forjou um perfil profissional voltado para a formação de seus alunos.

Palavras-chave: Educação Profissional; Formação Profissional; Processo Seletivo.

\footnotetext{
1 Possui mestrado em Educação pela Universidade Federal do Rio Grande do Norte (1999) e doutorado em Educação pela Universidade Federal do Rio Grande do Norte (2012).

2 Possui graduação em História (Licenciatura e Bacharelado), mestrado em História e doutorado em Educação pela Universidade Federal do Rio Grande do Norte. É professora do Centro de Educação da Universidade Federal do Rio Grande do Norte e atua como professora-orientadora no Programa de PósGraduação em Educação (UFRN) e no Programa de Pós-Graduação em Educação Profissional do Instituto Federal de Educação, Ciência e Tecnologia do Rio Grande do Norte.
} 


\section{Abstract}

This work aims to analyze, from 1942 to 1968 , how the Industrial School of Natal (EIN) organized its teaching staff in order to meet the demands of a curriculum focused on the formation of students who abide by established standards and, above all, able to carry out a professional activity. The theoretical-methodological framework used in this study focuses on the qualitative analysis, emphasizing the historical documents in the school archive, now called the Federal Institute of Education, Science and Technology of Rio Grande do Norte-IFRN. These are the official documents of the Direction of the School, books belonging to the Industrial School of Natal (1940 to 1959, 1960 to 1968), individual folders of teachers and photographs that reveal evidence of the process of formation of these teachers and of some of their educational practices. In this study, we highlight the analysis, mainly, of the Organic Law of Industrial Education (Decree-law No. 4,073 / 1942), Law 3,552 and Decree 47.038, of 1959, aiming to identify how this educational institution appropriated and used these different legislations in view of the process of constitution of the faculty of that school. We also favored the oral testimony of former teachers who were part of the faculty of the Industrial School of Natal during the period under study. The authors Julia (2001) and Fonseca (1961) help us to understand how a set of rules and actions developed within the scope of the EIN forged a professional profile focused on the training of its students.

Keywords: Professional Education; Professional Qualification; Selective Process.

\section{INTRODUÇÃO}

Este trabalho tem como objetivo analisar, no período de 1942 a 1968, como a Escola Industrial de Natal (EIN) organizou o seu quadro de professores em vista ao atendimento às demandas provenientes de um currículo voltado para a formação de alunos cumpridores das normas estabelecidas e, sobretudo, aptos ao exercício de uma atividade profissional.

O referencial teórico-metodológico utilizado neste trabalho se centra na análise qualitativa, dando ênfase aos documentos históricos existentes no arquivo da escola, hoje denominada Instituto Federal de Educação, Ciência e Tecnologia do Rio Grande do Norte-IFRN. Constituem o conjunto desses documentos portarias e ofícios da Direção da Escola, livros de posse da Escola Industrial de Natal (1940 a 1959; 1960 a 1968), pastas individuais dos professores e fotografias que expressam flagrantes do processo de formação desses professores e de algumas de suas práticas educativas.

Neste estudo, realçamos a análise, principalmente, da Lei Orgânica do Ensino Industrial (decreto-lei № 4.073/1942), da Lei 3.552 e do Decreto № 47.038, de 1959, objetivando identificar como essa instituição de ensino se apropriou e utilizou essas distintas legislações, tendo em vista o processo de constituição do corpo docente dessa 
escola. Também privilegiamos depoimentos orais de ex-professores que fizeram parte da Escola Industrial de Natal, no período em estudo.

Os autores Julia (2001) e Fonseca (1961) ajudam-nos a compreender como um conjunto de normas e ações desenvolvidas no âmbito da EIN forjou um perfil profissional voltado para a formação de seus alunos. Ademais, procuramos verificar as estratégias utilizadas pela Escola para aumentar o contingente de profissionais com formação adequada à nova educação profissional que se descortinava. Nessa perspectiva, respaldamo-nos em Julia (2001), quanto à análise da seleção de professores, em cada nível de ensino e os saberes e o habitus requeridos para um futuro professor.

No período de 1942 a 1968, o Governo Federal aprovou diversas leis direcionadas à organização do quadro docente das escolas da rede federal. Dentre elas, convém destacar, inicialmente, a Lei Orgânica do Ensino Industrial (decreto-lei no 4.073/1942).

Após a publicação da Lei Orgânica (BRASIL, 1942), é institucionalizada no processo de seleção de professores a exigência da formação em cursos apropriados, ou seja, em áreas que pretendiam atuar ou em áreas afins, o que significava ser detentor de uma formação específica. Nesse sentido, com a exigência da realização de processo seletivo (exame ou concurso), tentava imprimir uma nova configuração ao quadro de professores. Julia (2001, p. 30) expressa que a seleção de professores "[...] tanto na forma das provas como nos conteúdos dos saberes propostos aos candidatos, define a base mínima de uma cultura profissional a se possuir". Contudo, prevendo possíveis dificuldades na realização desse processo, a lei flexibilizava e garantia uma forma de acesso simplificada, sem a exigência da certificação dos conhecimentos por meio de exames teórico-práticos. Esse preceito legal possibilitou aos diretores dessas escolas o poder de influir, em determinadas ocasiões, na constituição do quadro de professores ao realizar contratações sem a realização de concurso público.

Apesar dessa flexibilização no processo seletivo, as escolas industriais e técnicas da rede federal continuavam enfrentando dificuldades de contratação de professores, principalmente, para as disciplinas de Cultura técnica.

$\mathrm{Na}$ Escola Industrial de Natal, no início dos anos de 1940, os obstáculos apresentavam-se em maior volume, devido ao atraso na organização dos cursos de Mestria $^{3}$ para a formação de mestres responsáveis pelo processo de formação efetuado

\footnotetext{
3 Como parte da organização do ensino profissional, a Lei Orgânica (1942) criou os cursos de 1ำ Ciclo. Dentre eles, o Curso de Mestria. Com duração de 2 anos, este curso tinha por finalidade formar os egressos do curso industrial básico para o exercício da função de Mestre na área em que havia se diplomado Artífice.
} 
nas oficinas. Esses cursos somente fizeram parte do seu currículo a partir do ano de 1945, tendo sua oferta suspensa no início dos anos de 1950.

Assim, devido a essas dificuldades de ausências de profissionais com o perfil adequado para assumir uma diversidade maior de disciplinas de Cultura técnica, para atender à demanda da estrutura curricular definida pela Lei Orgânica (Brasil, 1942), algumas ações foram empreendidas por essa escola e pelo Ministério da Educação, por meio da Divisão de Ensino Industrial (DEI) ${ }^{4}$, na organização das atividades formativas destinadas aos professores pertencentes aos quadros das escolas industriais e técnicas e aos ex-alunos selecionados para retornarem a essas instituições para o exercício da docência.

Como foco principal, essas ações tiveram como propósito assegurar a esses profissionais as condições técnico-metodológicas necessárias ao atendimento das finalidades do ensino industrial, definidoras das práticas educativas a serem desenvolvidas por essas Escolas, em tempos históricos diferentes, visando à preparação dos trabalhadores da indústria (Lei Orgânica do Ensino Industrial/1942) e proporcionar base de cultura geral e iniciação técnica que permitam ao educando participar do trabalho produtivo ou prosseguir os seus estudos (Lei 3.552/1959).

Dentre essas ações, torna-se importante destacar o acordo firmado entre Brasil e os Estados Unidos, que resultou na criação da Comissão Brasileiro-Americana de Educação Industrial (CBAI), em 1946.

Após a criação da CBAI, foi definido um vasto Programa de Ação, resumido em doze pontos. Dentre eles, destacamos o primeiro que garantia o "desenvolvimento de um programa de treinamento e aperfeiçoamento de professores, instrutores e administradores." (FONSECA, 1961, p. 565). Nas pesquisas sobre a oferta de capacitação para os professores da EIN constatamos algumas atividades pedagógicas de aperfeiçoamento, colocadas em prática pela DEI/CBAI. ${ }^{5}$

A CBAI passou a desenvolver, inicialmente, o projeto de qualificar os docentes que se encontravam em atividade, com a oferta de cursos de curta duração, no período das férias escolares, envolvendo certas especialidades industriais e artesanais tradicionais. Importa registrar que "ainda não haviam sido ativados os cursos pedagógicos previstos pela lei orgânica do ensino industrial para o $2^{\circ}$ ciclo do ensino industrial, de onde sairiam

\footnotetext{
4 Órgão subordinado ao Departamento Nacional de Educação do Ministério de Educação e Saúde (Lei 378, de 13 de janeiro de 1937).

5 Durante a vigência desse acordo, 1946-1961, segundo Falcão e Cunha (2009), a CBAI atuou de forma permanente no Rio de Janeiro/MEC - sua sede; em Curitiba, Escola Técnica Federal do Paraná, a partir de 1957; e em São Paulo, a partir da instalação da subsede junto à Secretaria Estadual do Trabalho.
} 
os docentes para as matérias de oficina para os dois ciclos" (FALCÃO; CUNHA, 2009, p. 165).

No âmbito interno da Escola Industrial de Natal, seguindo recomendação da Divisão do Ensino Industrial (DEI), foi oferecido um estágio em suas oficinas visando à capacitação dos professores de Cultura Geral e do Curso de Desenho. Essa atividade é registrada pela Portaria $n^{\circ} 36$, de 25 de junho de 1948, que se segue:

Tendo em vista o que ficou resolvido em reunião da Congregação de Professores desta Escola, realizada no dia 22 do corrente e em virtude:

I- das recomendações da Divisão do Ensino Industrial, por ocasião da segunda reunião dos Diretores realizada no Rio de Janeiro;

II- da necessidade de maior contato dos professores de Cultura Geral com os de Cultura Técnica, em benefício de um melhor entrosamento entre os dois ensinos,

Resolve:

a) realizar um estágio de todos os professores de Cultura Geral e Curso de Desenho nas oficinas desta Escola;

b) determinar que os professores estagiarão, pelo menos, em dois cursos diferentes e em disciplinas de sua escolha;

c) determinar que os trabalhos de aprendizagem sejam realizados durantes as férias regulamentares;

d) determinar que o tempo de estágio seja dividido em dois períodos de 15 dias cada um, sendo o primeiro de 1 a 15 de Julho vindouro e o segundo de 13 a 28 de fevereiro do próximo ano;

e) determinar que a aprendizagem seja iniciada diariamente às 8 horas $e$ concluída às 11, inclusive aos sábados, havendo às 9,30 um descanso de 10 minutos;

f) determinar que os trabalhos do estágio obedeçam à seriação especialmente organizada, não sendo permitido a execução de qualquer outro durante o tempo destinado à aprendizagem;

g) determinar que os professores chefes de Cursos, responsáveis pelos trabalhos dos estagiários, apontem, em cadernetas próprias a ausência de instruando, para efeito estatístico;

h) determinar que aos trabalhos executados, de acordo com o que ficou resolvido ainda em Congregação, sejam dadas notas de aproveitamento. (ESCOLA INDUSTRIAL DE NATAL, 1948a).

A decisão da Escola Industrial de Natal de desenvolver essa atividade de capacitação aos professores que lecionavam nas disciplinas de formação geral pode ser entendida como o reconhecimento de que era necessário integrar as práticas educativas dos professores, em um contexto em que o currículo dos cursos oferecidos por essa Escola era composto pelas disciplinas de cultura geral, práticas educativas, disciplinas técnicas e práticas de oficina. Constatamos, portanto, a crença de que, por meio desse estágio, os professores de cultura geral conseguiriam ter acesso aos saberes desenvolvidos nas oficinas - condição necessária para que o processo de integração entre as distintas áreas de conhecimento, de fato, pudesse acontecer. 
No processo de organização, foram definidos alguns critérios como, por exemplo, o número de cursos que o professor deveria estagiar, o tempo estabelecido para a sua realização, o controle de frequência pelo Chefe de Oficinas, além da avaliação do aproveitamento com atribuição de notas por esses profissionais.

$\mathrm{Na}$ ficha em que é registrada a distribuição dos professores aprendizes nos 5 (cinco) cursos existentes na EIN (Mecânica de Máquinas, Serralheria, Alfaiataria, Marcenaria e Artes do Couro), 15 (quinze) estavam relacionados. Dentre eles, o próprio diretor da EIN, Jeremias Pinheiro da Câmara Filho. Essa ficha contém o registro da escolha feita pelos participantes, o que incluiu a definição dos cursos e das disciplinas que seriam cursadas durante $01^{\circ}$ e $2^{\circ}$ estágios.

Imagem 1 - Distribuição dos professores - cursos e disciplinas. Estágios (1948 e 1949)

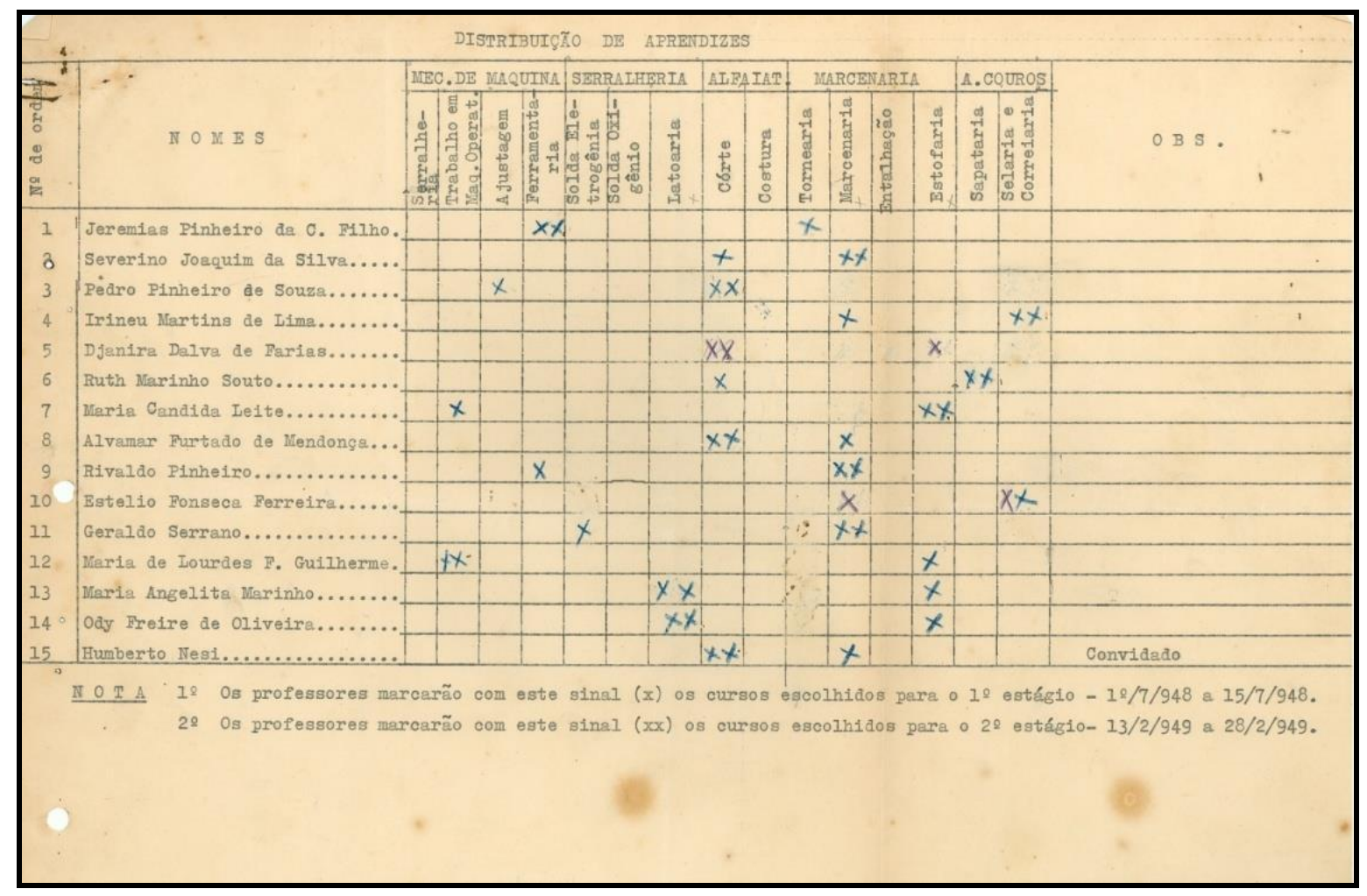

Fonte: (Escola Industrial de Natal, 1948b).

O referido estágio teria, como parâmetro de organização, a distribuição dos referidos professores em dois cursos diferentes (um para cada período do estágio), e, após esse processo, o candidato cursaria uma das disciplinas do curso escolhido. Observamos, portanto, que, no conjunto das disciplinas disponíveis - corte, marcenaria e estofaria - concentrou-se o maior número de estagiários. Essa escolha sugere que, na condição de aprendiz, os professores da EIN buscaram os conhecimentos mais 
sintonizados com a realidade cotidiana, disponíveis nos cursos de Alfaiataria e Marcenaria. $\mathrm{Na}$ imagem a seguir, é possível verificar o registro da presença dos professores nas oficinas reunidos com os mestres para iniciar a primeira parte do estágio:

Imagem 2 - Professores da cultura geral e os mestres das oficinas ${ }^{6}$.

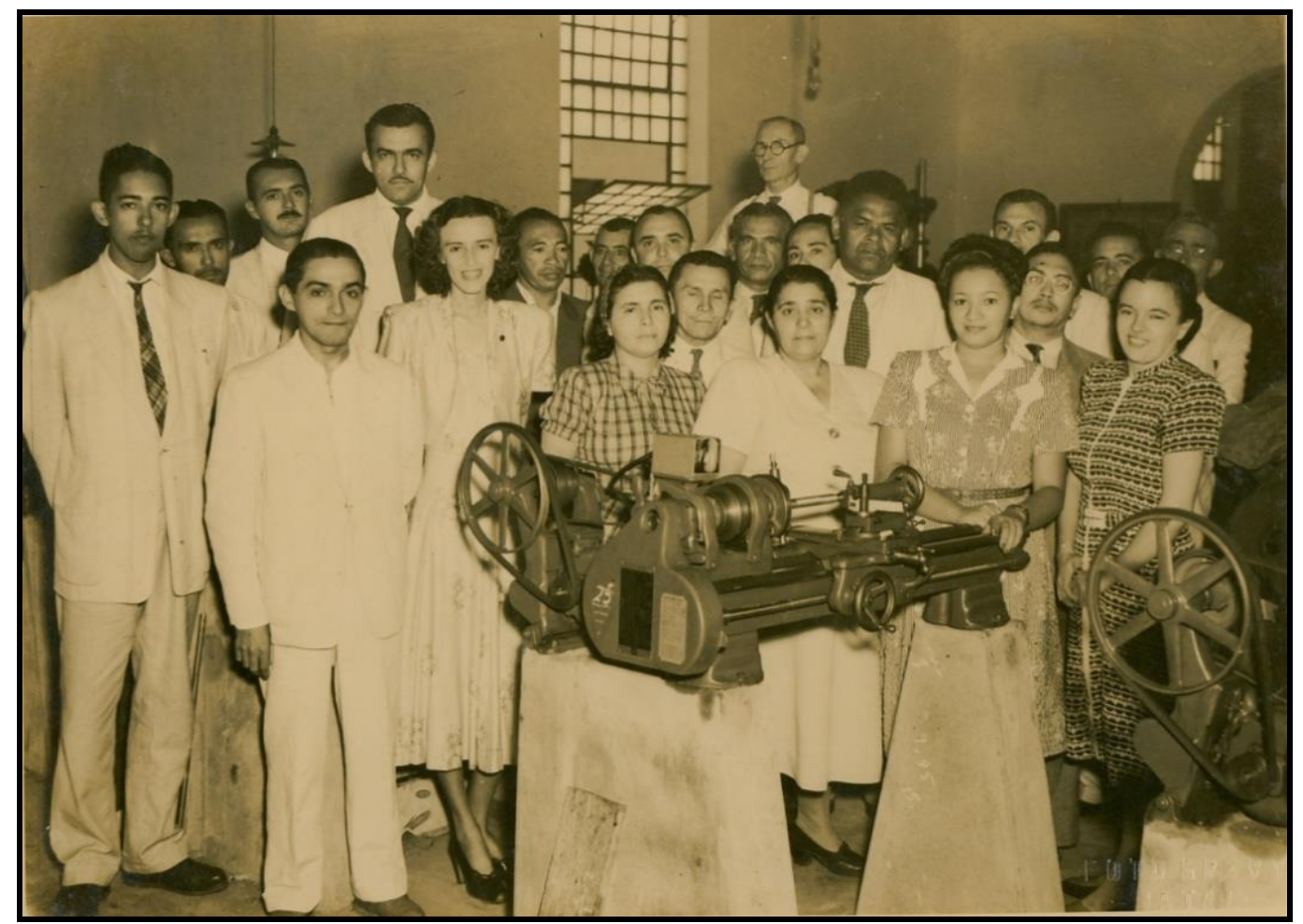

Fonte: Escola Industrial de Natal (1968).

É possível que a participação no referido treinamento tenha possibilitado a esse grupo de professores conhecer o desenvolvimento das oficinas, ambiente distante da maioria deles. Excetuando os professores de desenho - ex-alunos das escolas industriais -, os demais eram detentores de uma formação humanística, sem experiências anteriores em instituições de ensino profissional, conforme quadro a seguir:

\footnotetext{
${ }^{6}$ Início da $1{ }^{\text {a }}$ etapa do estágio nas oficinas - 1948.
} 
Quadro 1 - Professores da EIN contratados no período de 1940 a 1959

\begin{tabular}{|c|c|c|}
\hline \multicolumn{3}{|c|}{$\begin{array}{l}\text { Professores contratados no período de } 1940 \text { a1959 } \\
\text { (Dados coletados dos livros de posse da EIN (1940 a 1959) e das Pastas Individuais } \\
\text { dos professores). }\end{array}$} \\
\hline Nome do Docente & Nomeação/ldade & Cargo/Formação \\
\hline $\begin{array}{c}\text { Djanira Dalva de } \\
\text { Faria }\end{array}$ & 1940 (26 anos) & $\begin{array}{c}\text { Coadjuvante de Ensino - Desenho Ornamental. } \\
1944 \text { - Professora Ensino Industrial Básico. } \\
\text { Formação: ensino secundário. }\end{array}$ \\
\hline $\begin{array}{l}\text { Pedro Pinheiro de } \\
\text { Souza }\end{array}$ & 1940 (36 anos) & $\begin{array}{c}\text { Curso de Desenho. } 1944 \text { - Prof. Padrão J do } \\
\text { curso Industrial Básico. Formação: diplomas de } \\
\text { Artífice e Mestre, segundo familiares, adquiridos } \\
\text { na ETN-RJ. }\end{array}$ \\
\hline Romano & 1941 (38 anos) & $\begin{array}{l}\text { Curso de Sapataria. } 1944 \text { - Prof. Padrão J - Ens. } \\
\text { Industrial Básico. Formação: ex-aluno da EAA- } \\
\text { Natal. }\end{array}$ \\
\hline $\begin{array}{l}\text { Ody Freire de } \\
\text { Oliveira }\end{array}$ & 1943 (25 anos) & $\begin{array}{c}\text { Profa. Auxiliar curso primário. } 1945 \text { - Profa. de } \\
\text { Ciências Físicas e Naturais. Formação: Diploma } \\
\text { de Professora Primária na Escola Normal de } \\
\text { Natal (1935); Curso de Aperfeiçoamento na área } \\
\text { de Ciências Físicas e Naturais CBAl, RJ (1950). } \\
\text { Experiência anterior: Profáa . da Escola Isolada de } \\
\text { Jundiaí/Macaiba-RN (1936-1943). }\end{array}$ \\
\hline Maria Cândida Leite & 1943 (27 anos) & 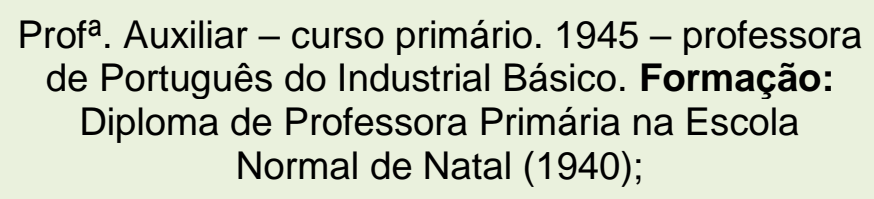 \\
\hline $\begin{array}{c}\text { Aurélio de Castro } \\
\text { Cavalcanti }\end{array}$ & 1944 (47 anos) & $\begin{array}{l}\text { Prof. Padrão G - Cadeira de Ajustagem - curso } \\
\text { de Serralheria. Padrão J - Formação: Curso de } \\
\text { Mecânica de Máquinas - EAA - CE. }\end{array}$ \\
\hline $\begin{array}{c}\text { Alvamar Furtado de } \\
\text { Mendonça. }\end{array}$ & 1945 (30 anos) & $\begin{array}{l}\text { Prof. Padrão J - Disciplinas: Higiene Industrial, } \\
\text { Organização do Trabalho e Contabilidade } \\
\text { Industrial - Curso de Mestria e Industrial Básico. } \\
\text { Formação: Bacharel em Direito. Ex-prof. de } \\
\text { Geografia no Atheneu Norte-rio-grandense. }\end{array}$ \\
\hline $\begin{array}{c}\text { Estélio Fonseca } \\
\text { Ferreira }\end{array}$ & 1945 (27 anos) & $\begin{array}{l}\text { Prof. Padrão J - Matemática. Formação: } \\
\text { Engenheiro Agrônomo - Escola de Agronomia de } \\
\text { Areias/Pb. }\end{array}$ \\
\hline
\end{tabular}




\begin{tabular}{|c|c|c|}
\hline Geraldo Serrano & 1945 (29 anos) & $\begin{array}{l}\text { Prof. de Educação Física - Padrão J - Práticas } \\
\text { Educativas. Formação: Escola Nacional de } \\
\text { Educ. Física - RJ, anos de 1940. Bacharel em } \\
\text { Direito na Faculdade de Alagoas - } 1956 \text {. }\end{array}$ \\
\hline $\begin{array}{l}\text { Irineu Martins de } \\
\text { Lima }\end{array}$ & 1945 (22 anos) & $\begin{array}{l}\text { Prof. Padrão J - Desenho de Móveis. Formação: } \\
\text { ex-aluno da EAA/EIN do Ceará e de Natal. } \\
\text { Diplomas de Artífice e de Mestre. Bacharel em } \\
\text { Direito - Faculdade de Direito/RN (1959); } \\
\text { Bacharel em Letras Neolatinas - Faculdade de } \\
\text { Filosofia - UFRN (1962). }\end{array}$ \\
\hline $\begin{array}{c}\text { José Augusto da } \\
\text { Silva }\end{array}$ & 1945 (26 anos) & $\begin{array}{l}\text { Prof. Curso de Marcenaria. Formação: ex-aluno } \\
\text { do Liceu Industrial de Natal - diploma de Artífice } \\
\text { em Marcenaria (1942). }\end{array}$ \\
\hline $\begin{array}{l}\text { Luiz Lunguinho de } \\
\text { Oliveira }\end{array}$ & 1945 (54 anos) & Prof. Curso de Artes do Couro. \\
\hline $\begin{array}{l}\text { Maria de Lourdes } \\
\text { Filgueira Guilherme }\end{array}$ & 1945 (34 anos) & $\begin{array}{l}\text { Práticas Educativas - Canto Orfeônico. } \\
\text { Formação: diploma de Canto Orfeônico no } \\
\text { Conservatório Nacional do Rio de Janeiro (1943); } \\
\text { Experiência anterior: profa. de Música/Canto } \\
\text { Orfeônico da Escola Normal de Natal (1938- } \\
\text { 1945); do Atheneu Norte-rio-grandense; Escola } \\
\text { Doméstica/Natal; Instituto Waldemar de Almeida } \\
\text { - Natal. }\end{array}$ \\
\hline Moacir Xavier & 1945 (29 anos) & $\begin{array}{l}\text { Prof. Ensino Industrial - Estofaria. Formação: ex- } \\
\text { aluno curso de Marcenaria do Liceu Industrial de } \\
\text { Natal e EIN. Curso de Aperfeiçoamento CBAl; } \\
\text { CBAI - TWI - Como ensinar um trabalho/Recife } \\
\text { (1956). }\end{array}$ \\
\hline Paulo Nobre Barreto & 1945 (23 anos) & $\begin{array}{l}\text { Curso de Marcenaria. Formação: ex-aluno Liceu } \\
\text { Industrial e EIN-Natal. Diplomas de Artífice e } \\
\text { Mestre. Exame de Suficiência para Prof. de } \\
\text { Tornearia do Curso Básico - expedido pela } \\
\text { DEI/CBAI (1956). }\end{array}$ \\
\hline $\begin{array}{c}\text { Pedro Martins de } \\
\text { Lima }\end{array}$ & 1945 (19 anos) & 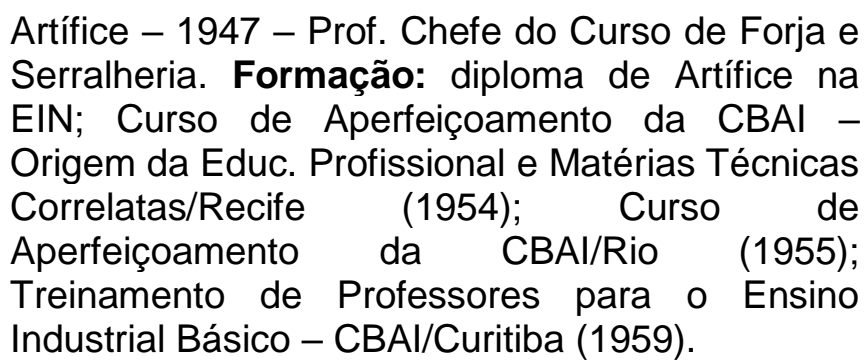 \\
\hline
\end{tabular}




\begin{tabular}{|c|c|c|}
\hline Rivaldo Pinheiro & 1945 (29 anos) & $\begin{array}{l}\text { Prof. de Matemática. Formação: Bacharel em } \\
\text { Ciências Jurídicas e Sociais - Faculdade de } \\
\text { Direito Alagoas (1949). Experiência anterior: prof. } \\
\text { de Matemática no Atheneu Norte-rio-grandense e } \\
\text { Repórter da Imprensa Oficial do RN (1939-1945). }\end{array}$ \\
\hline $\begin{array}{c}\text { Silas Paulino Raposo } \\
\text { da Câmara }\end{array}$ & 1945 (32 anos) & $\begin{array}{l}\text { Artífice - } 1946 \text { - Prof. Ensino Industrial - Forja e } \\
\text { Serralheria. Formação: ex-aluno EAA/EIN - } \\
\text { Artífice e Mestre. }\end{array}$ \\
\hline $\begin{array}{l}\text { Joaquim Inocêncio } \\
\text { Ferreira Filho }\end{array}$ & 1948 (24 anos) & $\begin{array}{l}\text { Curso de Alfaiataria - Cadeira Corte e Costura. } \\
\text { Formação: ex-aluno da EIN- Natal. Diplomas de } \\
\text { Artífice (1943) e Mestre (1946). Curso de Auxílio } \\
\text { Audiovisual e Matéria Correlata- CBAI/Escola } \\
\text { Téc. Recife (1954); Curso de Aperfeiçoamento } \\
\text { em Alfaiataria, Tecnologia e Direção de Oficinas } \\
\text { - CBAI/Recife (1956); Curso de Didática Especial } \\
\text { do Ensino Industrial - CBAl/Recife. }\end{array}$ \\
\hline $\begin{array}{l}\text { José de Góes } \\
\text { Vasconcelos }\end{array}$ & 1954 (27 anos) & $\begin{array}{l}\text { Artífice - Curso Artes do Couro. Formação: ex- } \\
\text { aluno da EIN - Diplomas de Artífice (1945) e de } \\
\text { Mestre em Artes do Couro (1949); Curso de } \\
\text { Aperfeiçoamento em Artes do Couro/CBAl } \\
\text { (1956); Curso Didática Especial do Ens. } \\
\text { Industrial/CBAl- Escola Técnica do Recife-PE } \\
\text { (1963). }\end{array}$ \\
\hline $\begin{array}{c}\text { Natanael Gomes da } \\
\text { Silva }\end{array}$ & 1954 (25 anos) & $\begin{array}{l}\text { Mestre - Curso de Alfaiataria; Anos } 1960 \text { - Prof. } \\
\text { de História nos cursos Industrial Básico e cursos } \\
\text { Técnicos. Formação: ex-aluno da EIN - diplomas } \\
\text { de Artífice e Mestre no Curso de Alfaiataria; } \\
\text { Bacharel e Licenciado em História - Faculdade } \\
\text { de Filosofia e Letras da UFRN, em } 1964 \text {. }\end{array}$ \\
\hline
\end{tabular}

Fonte: Escola Industrial de Natal (1940-1955).

No caso específico da Escola Industrial de Natal, esse quadro evidencia que os professores contratados, no período de 1940-1959, apresentavam o perfil então exigido para o ensino nos cursos industrial básico: a formação de mestres ou mesmo de artífice para a prática de oficinas, além da formação em escolas secundárias, para as disciplinas de cultura geral. Essa era uma estratégia permitida pela legislação em vigor para que as escolas pudessem superar, principalmente, as dificuldades de contratar professores, com uma formação técnico-profissional, em nível secundário, para as disciplinas técnicas e as práticas de oficinas.

É importante destacar que às escolas industriais até o final dos anos de 1950, não era permitida a oferta de cursos técnicos, mas apenas a oferta de cursos que garantiam 
aos alunos a formação industrial básica, o que reduzia, em parte, a sua dificuldade na constituição do seu quadro de professores.

No que diz respeito às disciplinas de Cultura geral, era nas escolas normal e secundária existentes em Natal que a EIN efetivava a contratação de profissionais com formação em nível secundário. Por outro lado, cabe ressaltar que nesse período essa escola já contava com um grupo de professores com formação em Nível Superior, em diferentes áreas (direito, agricultura, canto orfeônico e educação física). Nesse último caso, essa formação foi adquirida em escolas e faculdades localizadas em distintos Estados brasileiros, o que a tornava algo acessível apenas a poucos profissionais que exerciam o magistério nessa escola. Uma característica importante apresentada por esses professores era a comprovada experiência anterior no magistério, em outras instituições de ensino.

Outro dado que merece destaque, no caso específico das disciplinas de desenho e das práticas de oficina, é a identificação de ex-alunos dessa Escola e de outras instituições de ensino da rede federal. Esse fato notabiliza uma mudança no perfil do grupo anteriormente responsável pelo trabalho nas oficinas, já que os novos profissionais apresentavam uma formação com base em conhecimentos adquiridos na própria Escola Industrial, habilitando-os, portanto, a trabalhar nos cursos de $1^{\circ}$ ciclo, o industrial básico.

Em termos gerais, durante a trajetória no cargo, esses professores, inseridos nas diversas áreas de conhecimento dessa escola, conseguiram alterar seu perfil inicial de formação por meio de cursos de aperfeiçoamento ofertados pela CBAl e cursos em nível superior. Essa oferta de capacitação para os professores, pela DEI/CBAl, a rigor, até a segunda metade dos anos de 1950, caracterizou-se por sua carga horária reduzida, sendo ministrada no período de férias desses profissionais. Essa situação seria alterada a partir da criação do Centro de Treinamento de Professores na Escola Técnica de Curitiba (CPTP), em 1959, pelo Governo Juscelino Kubitschek.

Após a publicação da Nova Reforma do Ensino Industrial, em 1959, Lei 3.552, outra organização é estabelecida para as escolas industriais, agora com autonomia para ofertarem cursos técnicos, a exemplo do que já realizavam as antigas escolas técnicas ${ }^{7}$.

\footnotetext{
${ }^{7}$ Apesar dessa alteração na legislação, demoraria ainda alguns anos para que a EIN passasse a recebe a denominação de Escola Técnica. Assim, em 1965, é transformada em Escola Industrial Federal do Rio Grande do Norte e somente em 1968, torna-se Escola Técnica Federal do Rio Grande do Norte (ETFRN). Em 1999, outra mudança atinge essa escola, transformando-a em Centro Federal de Educação Tecnológica do Rio Grande do Norte (CEFET-RN). Essa nova denominação seria novamente modificada em 2008, com a transformação do CEFET-RN em Instituto Federal de Educação, Ciência e Tecnologia do Rio Grande do Norte (IFRN).
} 
Além dessa modificação em seu currículo, esta Lei ainda assegurou à administração das escolas a organização do quadro do pessoal docente e administrativo, atribuindo ao Diretor-Executivo, a sua coordenação, e ao Conselho de Representantes ${ }^{8} \mathrm{o}$ direito de aprová-lo.

Assim, pode-se assinalar que essa autonomia de definir e organizar o seu processo seletivo, assegurada à Escola Industrial de Natal, no final dos anos de 1950, forjou uma nova composição no quadro dos professores, com a contratação de homens e mulheres. Neste último caso em maior número do que nas décadas anteriores, com níveis diversificados de formação.

As informações contidas nos Livros de Posse e nas Pastas Individuais dos Docentes indicam crescimento na contratação de profissionais com habilitação em Nível Superior. Essa mudança alterou o perfil do quadro de professores dessa Escola, antes constituído, em sua maioria, por profissionais com formação básica adquirida nas próprias escolas da rede federal. Essa constatação sinaliza para a necessária especificidade de um estudo da formação profissional do professor, quanto à modalidade de profissionalização na qual está inserido.

Do ponto de vista da cultura escolar, as competências exigidas do professor primário eram "muito diferente daquela do professor secundário." (JULIA, 2001, p. 32.). Nesse sentido, cabe ressaltar que, na EIN, nos anos de 1960, as mudanças curriculares em prática no ensino industrial básico (Ginásio Industrial) e nos cursos técnicos de Ensino Médio tornavam desnecessária a presença dos antigos professores com níveis de formação primária. Além disso, fez surgir um conjunto de professores com nível superior, não apenas para a área de Cultura geral, mas também para as disciplinas de cultura técnica.

A nova composição do quadro de professores da EIN evidencia também a insignificante presença das mulheres no grupo de contratados para lecionar disciplinas de cultura técnica. Nesse sentido, vale registrar o relato da professora Maria de Lourdes Alves de Souza (2010), única professora a fazer parte desse grupo no final da década de 1960:

\footnotetext{
8 Este órgão, criado pela Lei 3.552/1959, era formado por representantes das indústrias, da Igreja, da Universidade Federal do Rio Grande do Norte, do Conselho Regional de Engenharia e Arquitetura e de um representante dos docentes da própria instituição e da comunidade. Vale destacar, ainda, que cabia a esse órgão, além de outras atribuições, eleger dentre os seus membros o presidente do próprio Conselho e definir, após a indicação de uma lista formulada pelos professores contendo nomes de seus pares, o Diretor Executivo da Escola.
} 
Após tomar conhecimento do concurso que selecionaria professores para a disciplina Artes Industriais na Escola Industrial de Natal, decidi fazê-lo. Quando eu cheguei à Escola para me inscrever, foi aquela surpresa, isso porque até então não existia mulheres ensinando nas oficinas. $O$ profissional que me atendeu foi logo me dizendo: "no processo de seleção terá aula de eletricidade, de madeira, vão Ihe apertar, pois terá que ensinar estes conteúdos." Mesmo diante disso, realizei a minha inscrição. Eu tinha estudado tudo isso no curso que fiz em São Paulo. Fui aprovada. (SOUZA, 2010).

O exemplo da professora que, apesar de atender às exigências do concurso, é recebida com ceticismo por representantes da EIN pode sinalizar a representação que setores dessa Escola tinham sobre o lugar que as mulheres professoras deveriam ocupar no exercício da docência. Por outro lado, a tímida presença feminina, na parte técnica do currículo, evidencia o que alguns estudos sobre a profissionalização e a inserção da mulher no mercado de trabalho/espaço público (LOURO, 2000; ALMEIDA, 1998; SAFFIOTI, 1976) tem revelado: a trajetória da formação das mulheres professoras, principalmente, até a primeira metade do século XX no Brasil, a conduzia para as Escolas Normais onde adquiriam a legitimidade para atuar no ensino primário, o que, na prática, distanciava-as de áreas como a do ensino industrial. E, quando conquistaram o direito de frequentar o nível superior, passaram a ocupar fortemente as áreas como Letras, Artes e Ciências Humanas.

Apesar dessa pouca participação feminina nos quadros técnicos da EIN, a nova legislação implementada no final dos anos de 1950, ao assegurar a transferência da atribuição de organizar o processo de seleção dos seus professores, antes centrada no Ministério da Educação/DEl, foi determinante na perspectiva da constituição de uma identidade institucional, já que o processo de seleção passou a ser elaborado, de forma autônoma, pela escola, conforme o art. 108, do Decreto nํ 47.038, de 1959.

Nesse sentido, após a aprovação dos cargos de pessoal pelo Conselho de Representantes, era assegurada a abertura das inscrições para o seu preenchimento, visto que esse Decreto, em seu art. 107, também prescrevia a "verificação de títulos, conhecimentos e capacidade, conforme o caso, além da investigação social." (BRASIL, 1959b). Em relação às exigências presentes na antiga Lei Orgânica (1942), continuava mantida a necessidade de os candidatos comprovarem que possuíam a formação adequada ao cargo preterido, o que exigia a realização dos concursos. Respeitando as especificidades próprias de cada área, essa legislação mantinha a avaliação dos candidatos por meio de atividades teóricas e práticas, assegurando a utilização de títulos acadêmicos para certificar o nível de conhecimentos. 
A professora Anaíde Dantas (2010), ao relatar seu ingresso na EIN, no ano de 1962, para a disciplina de História, destaca que em seu caso, a análise do currículo e títulos foi o critério utilizado para verificar se estava apta ou não para o exercício da docência, conforme relato a seguir:

[...] Um dia eu decidi ir a Escola Industrial de Natal e perguntei sobre o concurso ao diretor Irineu Martins de Lima que me respondeu: "nós temos uma candidata, mas é de Geografia e nós queremos de História". [...] Então, eu me apresentei e lhe disse que tinha o curso de História e ensinava na Escola Normal. Ele tirou da gaveta um papel e me perguntou se aquele horário me convém. Eu não quis nem saber, the respondi que sim. Eu the perguntei: mas, eu não tenho que fazer concurso? Ele disse: não! E acrescentou: "[...] eu não dou muito valor para concurso. O professor prepara a aula naquele dia e depois, às vezes, não leva muito a sério. Eu prefiro ficar observando. Traga o seu currículo". Foi dessa maneira que aconteceu o meu ingresso a essa Escola naqueles dias do mês de junho de 1962. (DANTAS, 2010).

A fala da Professora Anaíde Dantas (2010) traz à tona um exemplo das práticas desenvolvidas pela direção da EIN na composição do seu quadro de professores. Importa destacar que essa era uma das várias formas de contratação garantida pela nova legislação (Decreto $\mathrm{n} \cong$ 47.038, de 1959). Assim, era assegurada às Escolas a possibilidade de "admissão de docentes, através de contratos pelo prazo máximo de um ano, sem direito à renovação, mediante, apenas, apresentação de títulos." (BRASIL, 1959b). Essa forma de seleção se restringia aos casos em que, abertas as inscrições para preenchimento de vaga, não se apresentasse nenhum candidato e quando se tratasse de substituições eventuais ou transitórias.

$\mathrm{Na}$ constituição do quadro dos professores para o exercício das práticas nas oficinas, o então diretor da EIN, período de 1956-1962, Pedro Pinheiro de Souza, ao constatar ainda a existência da "escassez de professores", sugere o aproveitamento de ex-alunos do ensino industrial, segmento não presente na clientela inicialmente definida para fazer parte do processo de formação oferecido pela DEl/CBAI.

Nesse propósito, como critério de seleção, indica que sejam considerados os índices de aproveitamento e a avaliação do comportamento apresentados pelos alunos durante o curso. Observamos, portanto, que, ao sugeri-los, esse dirigente tentava garantir o maior poder de controle aos profissionais responsáveis por essa escolha. No caso específico da EIN, quando esse processo seletivo passou a vigorar, foi compartilhado pelo diretor, mestres e professores indicados por esse dirigente.

Assim, a partir do ano de 1960, a EIN passou a enviar para o Centro de Treinamento de Professores na Escola Técnica de Curitiba (CPTP) grupos de ex-alunos 
para o curso de Magistério de Artes Industriais, em uma das especialidades de trabalho (Artes Gráficas, Cerâmica, Desenho, Eletricidade, Madeira e Metal), para a primeira fase de Cursos Industriais Básicos e Ginásios Industriais. Isso contribuiu para alterar, nos anos seguintes, o perfil dos professores de cultura técnica e das práticas de oficina.

No Centro de Treinamento de Professores na Escola Técnica de Curitiba (CPTP), a escolha por uma formação geral que servisse para complementar os estudos já efetivados, o fortalecimento da formação prática e a inclusão de um conjunto de disciplinas voltadas para o campo da formação pedagógica indica a que público prioritário se destinava essa formação - o segmento ainda não preparado para a docência no ensino industrial. No caso da EIN, os ex-alunos dos cursos industrial básico. Sendo assim, é atribuído às disciplinas de Desenho e Práticas de Oficina um peso significativo. Complementando esse currículo, são acrescidas as disciplinas pedagógicas que subsidiarão o processo ensino-aprendizagem. Desse modo, o professor deve auxiliar o aluno em seu processo educativo, incluindo a formação geral, formação de atitudes e formação profissional, em sintonia com as finalidades do ensino industrial, expressas no art. 1으, do Decreto nํㅜ 47.038 de 1959.

Dentre os alunos encaminhados pela EIN, em 1963, ao Centro de Treinamento de Professores na Escola Técnica de Curitiba (CPTP), estava o ex-aluno do curso de Marcenaria, Antônio Fernandes de Carvalho. Em seu depoimento sobre a formação recebida nesse Centro, ele relata:

Era grande o nível de exigência, com a oferta de aulas teóricas e desenvolvimento das práticas nos laboratórios, em turnos distintos. Os conhecimentos eram para ser aplicados na Escola, para tanto, foi fornecido material em forma de apostila para ser trabalhado com os alunos quando estivéssemos em sala de aula. A disciplina para a qual fomos capacitados, Artes Industriais, ao trabalhar as noções básicas de mecânica, cerâmica, eletricidade, artes gráfica, deveria contribuir para pesquisar uma aptidão no aluno nas duas primeiras séries do $1^{\circ}$ ciclo, para que ele pudesse melhor fazer a sua escolha profissional para o $2^{\circ}$ ciclo, ou seja, o ensino técnico. (CARVALHO, 2010).

Assim, ao tentar assumir diretamente o controle da formação dos professores para as escolas de ensino profissional, o governo, por meio do órgão que coordenava a organização geral do ensino industrial, DEl/CBAI, objetivava possibilitar as condições necessárias para que, no exercício de suas práticas no interior da escola, esses profissionais contribuíssem, efetivamente, com o início da formação profissional nos ginásios industriais e o consequente aprofundamento nos cursos técnicos, conforme preconizava as diretrizes da Lei no 3552, de 1959, em vigor nesse momento. 
Evidenciamos neste estudo a luta permanente dessa instituição de ensino industrial na contratação de professores habilitados para as disciplinas de cultura técnica e para as práticas de oficinas. Frente a essa situação, a EIN passou a contratar ex-alunos, inicialmente, com formação de artífices ou de mestres. Nesse processo, identificamos também algumas iniciativas postas em prática pelo governo, nos anos de 1950 e 1960, com o propósito de capacitar professores dessa escola, por meio de cursos de curta duração voltados para as áreas onde atuavam.

Por fim, convém ressaltar que os estudos realizados nos permitiram desvelar que a preocupação dessa escola em constituir o seu quadro de professores estava relacionada ao cumprimento das políticas oficiais que orientavam a formação de artífices, mestres e, posteriormente, técnicos, com o propósito de torná-los aptos a exercer uma atividade profissional.

\section{REFERÊNCIAS}

ALMEIDA, J. S. Mulher e educação: a paixão pelo possível. São Paulo: Editora da UNESP. 1998.

BRASIL. Decreto-lei no $\div$ 4.073, de 30 de janeiro de 1942. Lei Orgânica do Ensino Industrial. Rio de Janeiro. 1948. Disponível em: <http://www.soleis.adv.br/leiorganicaensinoindustrial.htm>. Acesso em: 12 jul. 2007.

BRASIL. Lei 3.552, de 16 de fevereiro de 1959. Reforma do Ensino Industrial. Brasília, DF. 1959. Disponível em: <http://www.jusbrasil.com.br/legislacao/109459/lei-3552-59>. Acesso em: 5 out. 2007.

BRASIL. Decreto-lei no 47.038, de 16 de outubro de 1959. Regulamenta a Lei 3.552/59. Brasília, DF. 1959.

Disponível em: http://www2.camara.gov.br/legin/fed/decret/1950-1959/decreto-47038-16outubro-1959-386194-publicacaooriginal-1-pe.html.Acesso em: 6 de out.2007.

CARVALHO, Antônio Fernandes de. Sobre a Escola Industrial de Natal. Entrevistadora: Nina Maria da Guia de Sousa Silva. Natal, 9 e 23 fev. 2010.

DANTAS, Anaide. Sobre a Escola Industrial de Natal. Entrevistadora: Nina Maria da Guia de Sousa Silva e a Equipe da Coordenação de Comunicação Social do Campus Natal Central - IFRN, Natal, 6 de jun. 2010.

ESCOLA INDUSTRIAL DE NATAL. Portaria ํo 36, de 25 de junho de 1948a. [Trata do estágio de professores de Cultura Geral e Desenho, nas oficinas da EIN]. Natal, 1948. Arquivo do Campus Natal Central.

Fichas Individuais dos Professores da Escola Industrial de Natal a Escola Industrial Federal do RN, 1961-1968. Arquivo do Campus Cidade Alta - IFRN. Natal,1968. Manuscrito. 
- IFRN.

Fotografias - 1940-1968. Natal: [s.n., 1948b]. Arquivo do Campus Natal Central

Livro de Posse da Escola Industrial de Natal - 1940-1948. Natal, 1948. Arquivo Campus Cidade Alta - IFRN. Manuscrito.

. Livro de Posse da Escola Industrial de Natal - 1949-1955. Natal, 1955. Arquivo Campus Cidade Alta - IFRN. Manuscrito.

Livro de Posse da Escola Industrial de Natal a Escola Industrial Federal do RN, 1961-1968. Natal, 1968. Arquivo Campus Cidade Alta - IFRN. Manuscrito.

FALCÃO, Luciene Quintanilha; CUNHA, Luis Antônio. Ideologia, Política e Educação: A CBAI (1946-1962). Revista Contemporânea, Rio de Janeiro, v. 4, n.7, p. 148-173, jan.jul.,1999.

FONSECA, C. S. História do ensino industrial no Brasil. Rio de Janeiro: Escola Técnica Nacional. 1961. 1v.

JULIA, D. A cultura escolar como objeto histórico. Revista Brasileira de História da Educação, Campinas, n. 1, p. 9-43. 2001

SOUZA, Maria de Lourdes Alves de. Sobre a Escola Industrial de Natal. Entrevistadora: Nina Maria da Guia de Sousa Silva. Natal, 19 de mar. 2010. 